\title{
LER - LESÕES POR ESFORÇOS REPETITIVOS: UMA REFLE- XÃO SOBRE OS ASPECTOS PSICOSSOCIAIS*
}

\author{
Marcia Elena Rodrigues Gravina**
}

RESUMO: O objetivo deste estudo foi o de contribuir para a compreensão dos fenômenos que envolvem as LER e sua relação com o mundo do trabalho, refletindo sobre a multiplicidade dos fatores, dando ênfase à dimensão psicossocial a partir de depoimentos de pessoas com LER. A opção foi pela metodologia qualitativa e, pelas caracteristicas da pesquisa, o instrumental escolhido foi o estudo de caso. Foram realizadas entrevistas com quatro bancárias com diagnóstico de LER e que estavam afastadas do trabalho. As entrevistas foram realizadas individualmente utilizando-se um roteiro semi estruturado, em data e horários previamente marcados e tiveram a duração media de duas horas cada uma. As pessoas apresentaram: descrédito no adoecimento; insatisfação e revolta por não poder mais fazer coisas importantes para a vida pessoal; dificuldades em mostrar a doença e fazer com que os outros acreditem nela; falta de reconhecimento pelo trabalho realizado; perda de identidade; ansiedade pelo desconhecido; estado de estresse e esgotamento muito acentuado; limitações impostas pela doença. Em conclusão pode ser apresentado: interferência da organização do trabalho e das relações de trabalho no adoecimento; o sofrimento físico que antecede e precede o adoecimento; onipresença da dor e as limitações impostas em nível físico e mental que impossibilitam projetos de vida; dificuldades no diagnóstico e tratamento; comprometimento da vida pessoal e familiar.

PALAVRAS-CHAVE: Lesões por Esforços Repetitivos; Aspectos Psicossociais; Trabalho bancário.

\footnotetext{
* Resumo da Dissertação de Mestrado apresentada no Departamento de Saúde Ambiental da Faculdade de Saúde Pública da Universidade de São Paulo

** Fonoaudióloga, Mestre em Saúde Pública e relacionamento integrado de RH da Caixa Econômica Federal. e-mail: marcia.gravina@caixa.gov.br
} 


\section{AS TRANSFORMAÇÕES NO MUNDO DO TRABALHO E A AUTOMAÇÃO BANCÁRIA}

Um marco nas relações de trabalho se dá a partir da Revolução Industrial que teve seu início no Século XIX na Europa, seguida da América do Norte e modificou a vida das pessoas. Grupos familiares abandonaram o trabalho autônomo de artesanato para se dedicar às atividades fabris onde pouca ou nenhuma habilidade era exigida, devido ao uso das máquinas.

Foi o começo da era industrial e do capitalismo e, para alcançar a produção desejada era necessário o uso de métodos de trabalho diferentes. Foram muitas as tentativas de codificar a administração e torná-la o mais científica possível. Vários estudiosos se concentravam em procurar formas pormenorizadas de controle e métodos com a intenção de atender às exigências de produtividade determinadas pela nova sociedade. Entre eles foi importante a contribuição dada por TAYLOR, um engenheiro americano que escreveu Princípios da Administração Científica, na primeira metade do Século XX. Na mesma época Ford procurou operacionalizar a demanda existente entre consumidores potenciais através da criação de um modelo de carro que pudesse ser dirigido por qualquer pessoa. Para tanto criou um sistema adequado ao pronto atendimento de produção.

A principal característica deste tipo de produção foi a separação entre a mente e o corpo, ou seja para a produção não é necessário utilizar a inteligência ou a criatividade, o homem está destinado a produzir. Apesar de terem sido realizados estudos a respeito das necessidades humanas e da motivação, a influência da administração científica é muito forte e perdura até hoje, podendo ser notada em muitas cadeias de refeições rápidas, linhas de montagem das fábricas, escritórios, entre outras.

O processo histórico mostra um investimento cada vez maior na tecnologia ocorrendo uma diminuição da participação do trabalhador no processo produtivo. As modificações acentuam-se fundamentalmente nos países de capitalismo avançado, principalmente na estrutura produtiva, na representação sindical e política.

Como o presente estudo foi feito em um banco é importante se abordar as repercussões da automação bancária, uma vez que foi em torno dela que se deu a forma de organização do trabalho no setor. A automação está ligada à agilização de procedimentos bancários, visando o oferecimento de serviços e produtos com rapidez e segurança. 
Em 1964, como política governamental, foram criados os CPD - Centro de Processamento de Dados, quando grandes computadores controlavam as informaçōes financeiras do país. No final dos anos 70 foi introduzido o sistema on-line, exigindo uma melhoria nas telecomunicações no país. No final dos anos 80 houve uma intensificação do uso do sistema, com a implementação de serviços de auto atendimento e homebanking. A partir dos anos 90 destacam-se ações inovadoras como banco virtual, caixas eletrônicos, cartões magnéticos, etc. As máquinas fazem a maior parte do serviço.

A automação bancária brasileira proporcionou mudanças no relacionamento do banco com os clientes, fazendo-os operar com a tecnologia de ponta, que já está incorporada no cotidiano das pessoas.

Isto porque, a não ser para clientes especiais, os bancos não têm estimulado o contato com as pessoas, pelo contrário, o objetivo é fazer com que os clientes não compareçam às agências bancárias, se tornem virtuais. Para os bancos a automação traz aumento de mercado, além da redução de custos, pois diminuem as tarefas de contabilidade e compensação. Por outro lado, com relação à organização do trabalho ocorre um aumento do volume e padronização das tarefas, crescendo também o controle sobre tempos e qualidade dos serviços. As máquinas acabam fazendo a maior quantidade de trabalho, desqualificando a experiência profissional, tornando o bancário um trabalhador facilmente substituivel.

Em estudo realizado pelo DIESAT (1989), foram identificadas como características da atividade bancária: compartimentalização das atividades; rotinas individualizadas; extrema divisão de tarefas; possibilidade de rápida substituição do empregado; ritmo acelerado; períodos de maior atividade fazendo com que o trabalhador esteja em constante estado de tensão. O mesmo estudo aponta como fontes de tensão e cansaço: ritmo intensivo; prolongamento da jornada de trabalho; controle; pressão; responsabilidade excessiva; natureza e conteúdo das tarefas; plano de carreira insatisfatório; risco de assalto; atenção concentrada; ruído no ambiente de trabalho; etc.

Algumas das conseqüências deste tipo de organização do trabalho são: cansaço generalizado; dores no corpo; infecções da garganta e resfriados; gastrites e úlceras; varizes; crises mentais; queda da motivação; dificuldades de socialização.

A automação trouxe repercussões para a vida do bancário tanto com relação à sua desqualificação profissional; quanto a sua saúde. Ou seja ao que tudo indica a sobrecarga 
quantitativa expressada pela necessidade de produção, aliada ao requisito qualitativo, que significa ser eficiente e eficaz, acabam provocando cansaço e extrema fadiga mental.

\section{LER - LESÕES POR ESFORÇOS REPETITIVOS}

As Lesões por Esforços Repetitivos não são doenças novas para a Medicina do Trabalho, em 1700, RAMAZZINI em seu trabalho De Morbis Artificum Diatriba, descreveu as Doenças dos Escribas e Notários. Mas é a partir da Revolução Industrial que começam a aparecer casos com maior freqüência, intensificando-se com a mecanização da produção, principalmente com o advento do computador e mais recentemente a automação.

Praticamente no mundo todo a doença já foi reconhecida entre os trabalhadores. MAEDA (1997) coloca que no Japão em 1958 foram descritos os primeiros casos de Occupational Cervichobrachial Disorder. Na Austrália, a doença teve seu conceito definido por BROWNE et al (1984) em 1970 com o nome Repetitive Strain Injuries. Na Suíça as pesquisas vem sendo feitas a partir de 1980 coordenadas por HUNTING et al (1981). Nos Estados Unidos, ARMSTRONG (1986) apresentou o conceito de Cumulative Trauma Disorders citanod síndorme do túnel do carpo e tendinites como exemplos típicos.

No Brasil a primeira preocupação com esta patologia partiu de AHMED ALI, médico que investigou a sua ocorrência em agências bancárias no sul do país. Em 1973 foram apresentados casos em lavadeiras, limpadoras e engomadeiras no XII Congresso Nacional de Prevenção de Acidentes. Com a luta dos profissionais de processamento de dados, em 1986, o INAMPS - Instituto Nacional de Assistência Médica e Previdência Social reconheceu a tenossinovite como doença do trabalho nas atividades de esforço repetitivo. A partir de pressões dos trabalhadores, em 1990, o Ministério do Trabalho alterou a Norma Regulamentadora 17 atualizando-a. A mais recente alteração foi a publicação da Ordem de Serviço no 606 de 5/8/98 do INSS - Instituto Nacional da Seguridade Social que estabeleceu atualização clínica e critérios para a avaliação da incapacidade laborativa, instituindo para tanto a denominação DORT - Distúrbios Osteomusculares Relacionados ao Trabalho.

Para este estudo foi adotada a descrição da Secretaria de Estado de Saúde de São Paulo (1992) que diz: "LER é um conjunto de afecções que podem acometer tendões, sinóvias, músculos, nervos, fáscias e ligamentos, isolada ou associadamente, com ou sem degeneração de tecidos, atingindo principalmente, porém não somente, membros superiores, 
região escapular e pescoço, sendo de origem ocupacional e decorrente, de forma combinada ou não de: uso repetitivo de grupos musculares, uso forçado de grupos musculares e manutenção de postura inadequada."

A revisão bibliográfica mostra uma preocupação a nível mundial com relação às LER, apontando para a sua magnitude e complexidade. O diagnóstico é essencialmente clínico ocupacional, abrangendo o exame físico detalhado, exames complementares (quando justificados) e a análise das condições do trabalho responsáveis pelo aparecimento da lesão. Os sintomas são diferentes para cada tipo de lesão, assim como as patologias.

Quanto aos fatores de risco para o desenvolvimento das LER, eles estão relacionados ao posto de trabalho (grau de adequação às condições físicas do trabalhador; existência de vibrações, frio, pressões sobre os tecidos; mobiliário inadequado); manutenção de posturas inadequadas; carga osteomuscular; carga estática; invariabilidade da tarefa; exigências cognitivas e fatores organizacionais e psicossociais.

Alguns estudos têm abordado a questão da influência dos aspectos psicossociais no desenvolvimento das LER. Por exemplo BONGERS et al (2000) desenvolveram estudo epidemiológico cujo resultado apontou para uma forte evidência de que falta de apoio social e insatisfação no trabalho se constituem em fator de risco para as LER. RIBEIRO (1997) apresenta em seu artigo a hipótese de que existe uma dimensão social mais abrangente que contem duas outras a que ele chamou de dimensão do trabalho, relativa ao processo e organização do trabalho, e uma outra a dimensão individual, que trata da forma como cada um percebe o mundo. Avançando na sua análise formula outra hipótese que diz respeito ao fato de alguns indivíduos adoecerem e outros não, submetidos, teoricamente, ao mesmo processo produtivo: "A impropriedade do adoecimento não está na pessoa, posto que lhe é externa, mas no trabalho." (RIBEIRO, 1997, p. 92).

Considerando todos estes aspectos, este estudo teve como objetivo contribuir para a compreensão dos fenômenos que envolvem as LER, com ênfase na dimensão psicossocial, a partir de depoimentos de pessoas com LER.

\section{PROCEDIMENTOS METODOLÓGICOS}

Pelo dicionário (LUFT, 1994) um dos significados para método é "Ordem seguida na investigação, no estudo, na persecução de qualquer objetivo". CHAUí (1994) diz que 
methodos é um planejamento que se segue para a realização de uma investigação com o intuito de se conhecer alguma coisa. Assim, o método se torna uma escolha entre várias possibilidades e portanto deve ter critérios ligados ao pesquisador e à pesquisa.

MINAYO (1992) coloca que as Metodologias Qualitativas podem ser entendidas como aquelas que conseguem incorporar o significado e a intencionalidade como pertencentes às relações e às estruturas sociais, dando sentido à construções humanas significativas. A mesma autora afirma que o objeto das ciências sociais é essencialmente qualitativo, tendo em vista que ele é histórico, ou seja possui consciência histórica; tem a característica da identidade entre sujeito e objeto; além de ser intrínseca e extrinsecamente ideológica.

Partindo destas considerações optou-se pela metodologia qualitativa, levando-es em conta que o objetio é o da compreensão de um fenômeno com a preocupação de apresentá-lo na perspectiva das pessoas que foram pesquisadas. Entre as diversas formas que a pesquisa qualitativa pode assumir, foi escolhido o estudo de caso, dadas as suas peculiaridades.

LÜDKE E ANDRÉ (1990) apontam as seguintes características do estudo de caso:

- $\quad$ visam à descoberta: mesmo havendo pressupostos teóricos iniciais, haverá sempre o contato com o novo, partindo do princípio que o conhecimento não é algo acabado;

- $\quad$ enfatizam a interpretação em contexto: é preciso levar-se em conta em que contexto o sujeito está inserido;

- buscam retratar a realidade de forma completa e profunda: apresentam a multiplicidade de dimensões presentes na situação a ser estudada;

- revelam uma experiência vicária e permitem generalizações naturalísticas: a generalização ocorre em virtude do conhecimento experencial do sujeito, o leitor pode refletir em que sentido este caso se aplica no seu próprio caso.

Desta forma a preocupação central do estudo de caso é a compreensão de uma instância singular em que o objeto de estudo é tratado como único, como representação singular da realidade que é multidimensional e historicamente situada (LÜDKE e ANDRÉ, 1990). O estudo de caso parte do princípio de que o leitor terá acesso a um conhecimento que lhe permitirá desenvolver novas idéias. 
Para a realização da pesquisa foram selecionados trabalhadores em agências de um mesmo banco localizadas na cidade de São Paulo, afastados do trabalho, com diagnóstico de LER, reconhecidos pelo INSS como acidente de trabalho. A escolha do número de trabalhadores entrevistados se deu em relação à qualidade e diversidade de informações adquiridas. As entrevistas foram marcadas, por telefone, em local e horários mais adequados para ambas as partes sendo que a maioria se deu nas residências das trabalhadoras. As entrevistas tiveram duração média de duas horas cada uma e foram gravadas com o consentimento das trabalhadoras, sendo transcritas logo após.

Foi utilizado um roteiro básico (anexo), porém sem prejuízo à colocações e questões aleatórias ligadas ao tema. As entrevistadas são Elisabete, Ana, Marina e Sandra que coincidentemente trabalham em média 17 anos no mesmo banco. Antes do afastamento do trabalho, três eram caixas e uma delas trabalhava em um serviço interno que englobava digitação, emissão de relatórios e certificados, conferências, lançamentos e bloqueios diversos, atendimento telefônico e supervisão de pessoas.

LÜDKE E ANDRÉ (1990) apresentam a importância da determinação de contornos e focos de investigação, no estudo de caso, considerando-se que não é possível explorar todos os aspectos de um problema em um determinado espaço de tempo. Dessa forma é importante selecionar os recortes para se chegar a uma compreensão mais completa do estudo.

No presente estudo, a partir dos depoimentos, foram separados os seguintes temas de análise: as relações de trabalho dentro da nova forma de capitalismo; as relações sociais no trabalho; as estratégias pessoais; a LER como uma resposta ao sofrimento no trabalho..

\section{RESULTADOS}

\section{Sentimentos e vivências ambíguas dentro da nova forma de capitalismo}

A grande maioria das pessoas que trabalham no banco ingressaram há mais de dez anos, quando a empresa, assim como outras empresas, tinha objetivos e formas de trabalho diferentes dos atuais. Existe um certo clima de nostalgia com relação ao ambiente.

Elisabete na sua fala se refere a esta mudança: "Eu tenho amigos, mas da época que eu entrei, naquela época tudo era mais aberto, um ia apresentando o outro. Mas lá na 
agência eu tenho colegas, fica ali na unidade mas não sai dali muito, a gente não freqüenta a casa”. Em outro trecho ela fala: “A própria deterioração da ........(empresa) que está havendo ao longo do tempo, acho que o ambiente de trabalho já foi melhor, hoje está mais tenso, a gente recebe ,mais pressões....".

As empresas de modo geral para sobreviverem, atendendo a novas demandas de mercado, eliminam ou redesenham cargos e funções e, em muitos casos, operações inteiras. Transitam entre processos produtivos, utilizando-se de quaisquer recursos disponíveis que possam garantir e aumentar seus ganhos.

O banco estudado estando dentro deste contexto teve que se adequar às novas situações, com o objetivo de se capacitar para atuar no mercado financeiro. Acompanhando as mudanças passou por diversos processos administrativos de reengenharia, terceirização de serviços que não sua finalidade; implantação do Programa de Qualidade Total.

Foram alteradas as formas de trabalho, transformando-se em estações com atividades específicas em cada uma delas, mudando inclusive o seu aspecto visual. $O$ seu objetivo atualmente está voltado para o atendimento ao cliente, incrementando de maneira definitiva a venda de produtos da empresa, proposta totalmente inversa daquela vivenciada há dez anos atrás.

Esta nova postura da empresa é que dá forma à nostalgia e tem sido sentida com muito desgaste pelos empregados, existindo inclusive um sentimento de indignação.

Elisabete conta uma situação que vivenciou recentemente: "Outro dia eu estava na agência, às vezes eu vou como cliente na agência, eu fico olhando de fora. Eu vi um caixa lá, ele tinha uma fila, ele era o único caixa que estava atendendo clientes, tinham dois atendendo não clientes. Acho que tinha umas cinco pessoas na minha frente, haviam seis pessoas na fila. Ele estava oferecendo seguro, entre um cliente e outro. Ele ainda era obrigado a vender! Entendeu? Então você é um vendedor?'

Esta situação se configura na descaracterização do papel que as pessoas exerciam. Há uma incongruência entre aquilo para o que elas foram contratadas e o que se exige delas atualmente. 


\section{As relações sociais no trabalho: conciliação ou mudança?}

As relações sociais no trabalho também sofreram mudanças, no banco pesquisado existe uma visão das gerências como líderes educadores, responsáveis pela definição da estratégia de atuação da unidade e pela realização de negócios, atuando na captação e aplicação de recursos visando o atingimento de metas.

A forma de seleção de um gerente se dá a partir da candidatura de empregados da própria unidade, logo após os eleitos irão passar por testes e provas antes da escolha definitiva.

Desta maneira procura-se dividir com a equipe a responsabilidade pela escolha, porém o compartilhamento com a equipe e o líder, não consegue garantir que não haja abuso do poder. Nos relatos das pessoas entrevistadas isto é um fator de sofrimento no trabalho.

Ana, por exemplo, chama a atenção para a ausência de algumas gerências e as ameaças de outras: "O gerente geral era ausente, ele fazia contatos externos, a gente quase não tinha relacionamento com ele. Ele era bacana, mas não exercia a chefia diretamente." "...... gerente de produto que era a que tinha que captar era muito nariz empinado e queria só mandar". Essa chegava e dizia assim: "Passa esse malote". E se eu falasse assim: "Mas eu estou aqui desde às 8 horas, não dá mais, pede para outro que entrou às 10 horas, eu já estou saindo". Ela fazia aquela ar, olhava no relógio, ameaçava cortar vantagens, por exemplo não vai poder tirar férias em janeiro, não vai poder tirar folga no feriado, aqueles deltas que a gente ganhava, ela falava com freqüência:

"Isso, quem não passa malotinho, quem não fica depois não vem chorar." Tinha também a distribuição de horas extras..." quem não colaborar, não venha querer ganhar as horas extras.".

Para Marina, a pressão era muito grande também: "Eu trabalhava com uma gerente que eu posso te garantir que a agência inteira não gostava dela. E eu trabalhava com ela, as pessoas falavam: "Não sei como você agüenta trabalhar com ela!'. Ela era minha chefe imediata, tinham outras pessoas no setor, mas funcionário ali era praticamente só eu.

Porque o restante eram estagiários e funcionários contratados. Eram digitadores, eu era a única funcionária mesmo, então ela exigia muito porque a gente trabalha num 
sistema de senha, então só eu e ela tínhamos a senha. A coisa começou a piorar para o meu lado porque eu, modéstia parte, sempre trabalhei muito. Só que aí a gerente passou a exigir demais, ela como gerente mesmo, acabava deixando muitas coisas dela para eu estar fazendo e usando a senha dela. "....Então ela jogou tudo para mim, dizendo que eu daria conta." ".... Ela só supervisionava mesmo e eu comecei a me sentir pressionada e até com medo mesmo...."

Talvez numa tentativa mais de aliviar o peso da responsabilidade do que em ser uma liderança educadora e repartir tarefas, a gerente passou a atribuir tarefas, que eram de sua responsabilidade, para Marina: "Então eu me sentia com uma responsabilidade muito grande mesmo e comecei a tentar reverter isso. Só que naquela agência, eles não davam muita atenção no geral. ....Nós tínhamos um gerente geral que não dava atenção. Eu cansei de sentar na mesa dele e falar; e eu ouvia: "Não, você está nervosa, você não está bem, dá para você fazer!" E eu sabia que não dava, só que sentia ninguém me ouvia."

Com Sandra, percebe-se um nível de violência psicológica e discriminatória, assim como abuso do poder: "..quando eu voltei da licença maternidade, eu já voltei grávida, mas não foi uma coisa planejada. Ninguém planeja ter quatro filhos nos dias de hoje."

“...E com tudo isso eu volto a trabalhar e a minha recepção foi péssima. Porque eu voltei e já avisei logo, estou grávida. Porque eu não gosto de enrolar. Aí ela (gerente) falou: "Sobe numa pia e pula, para ver se você perde. Ou então fica esmurrando, faz alguma coisa!" Eu falei para ela: "Porque você está fazendo isso comigo?" Ela respondeu: "Isso é coisa de nordestino mesmo, de cearense, ter um monte de filhos."

Além disso, ocorre também falta de reconhecimento do trabalho realizado, aspecto de maior relevância uma vez que o homem tem uma história de eterna busca de reconhecimento dos outros e de auto estima. Sandra foi uma das pessoas que investiu muito no trabalho acreditando em recompensas: “...E na época que eu fui para a agência eu trabalhava direitinho", então o gerente falou assim: "Estou precisando de uma pessoa que se responsabilize pelas contas inativas". Então eu fiquei responsável por isso. Ele me disse que havia uma chefia de setor e que quando viesse era minha, porque eu tinha feito tudo, tinha cuidado. Eu entrava vinte para às sete da manhã, saía de lá dez horas da noite! Trabalhei sábado, domingo..... Quando a agência mudou da Vila Madalena para a Vila Romana foi sábado e domingo a mudança, eu trabalhei sábado e domingo. Só que na hora que veio a chefia, foi para uma outra pessoa, que nunca desceu! Eram dois andares, ela nunca desceu da sala dela para atender um cliente! Eu tive vontade de chorar! 
As relações com os colegas de trabalho também não andam satisfatórias. Os relatos são de competitividade entre as pessoas tornando as relações superficiais.

Elisabete apresenta o seguinte depoimento: "Eu por exemplo, na agência tenho colegas e não amigos. Tem pessoas legais que eu até gostaria de me aproximar, mas pelas circunstâncias não foi possível. .....Mas lá na agência eu tenho colegas, fica ali na unidade, não sai dali, a gente não freqüenta a casa".

As "circunstâncias" a que ela se refere dizem respeito à impossibilidade de se conversar sobre outros assuntos que não sejam de trabalho, devido ao excesso de atividades e ao cansaço que se apresenta no final do dia. No modelo econômico atual é celebrado animadamente o trabalho em equipe. As tarefas, as metas são divididas entre a equipe, são necessárias aptidões de saber ouvir e repartir, ser cooperativo e adaptável. E a superficialidade contribui para deixar o grupo unido sem conflitos interpessoais.

Marina sentiu isso próximo quando ocorreu a implantação da nova forma de trabalho na empresa. Só que o que aconteceu foi uma total falta de entrosamento, o que já era pouco virou quase nada: "Quando veio esse ....(novo modelo administrativo) que, para mim foi um desastre que aconteceu na vida dos empregados do (banco), porque as pessoas não entenderam o ....(novo modelo administrativo), principalmente o gerente. Criou-se as estações, tinha atendimento, etc e cada um achava que o outro era o que tinha que fazer: "Isso não é meu, isso é seu!" Ficou essa troca de pressão, isso não é meu, isso é seu. Alguns achavam que não tinham que fazer mais nada. O meu setor ficou tipo uma retaguarda e acaba tudo ali. E o clima piorou entre as pessoas. Tudo era a gente, tudo que era rolo que aparecia, ninguém queria mais resolver. As pessoas do atendimento achavam que tinham que ver o que era e passar para alguém e geralmente caía nesta área que é o suporte. Aquilo não era suporte (risos) porque ninguém agüenta isso! Porque tudo era no suporte, surgiu um esquema de guerra dentro da agência!

\section{Estratégias pessoais na atual situação de trabalho}

Um outro aspecto abordado nas entrevistas foi a estratégia pessoal no trabalho. Cada uma delas tem uma forma de desenvolver suas atividades diárias. Mas foi possível identificar entre elas uma necessidade de que tudo seja feito da melhor maneira e que o resultado seja perfeito. Elas se sentem desconfortáveis com a idéia que os outros possam 
ter com relação a erros no seu trabalho. Elisabete em seu depoimento fala sobre sua estratégia: "É assim, eu chegava, procurava fazer meu serviço e não me envolvia naquela loucura. Eu via uma fila e tentava me concentrar, eu vou atender um de cada vez". Pensava: "Tudo bem!' É claro que estressa ver uma fila. Mas você sabe que tem colegas atendendo. Agora de frente para o público, você não fica muito à vontade, por exemplo para atender um telefone, eu evitava ao máximo.

Um outro aspecto abordado por Elisabete foi quanto às atribuições do caixa que além de numerosas, exigem atenção e concentração em demasia, influenciando também a possibilidade de ocorrência de estelionatos e assaltos: "...Por exemplo nos casos de estelionato, a gente convivia diariamente com esse problema. Cada cliente, a não ser aquele que você já conhece, cada cliente novo que vem na tua frente, a princípio é um estelionatário. Então você tem sempre que estar atenta. Eu mesma passei duas vezes por golpe de estelionatário. Da primeira vez a perícia deu como boa a falsificação...E a segunda eu tive que pagar quase $R \$ 2000,00 . . . "$.

Ana fala de sua estratégia: "No caixa era um verdadeiro ritual, tinha a seqüência de tudo. Por isso quando dava algum erro eu sabia onde tinha acontecido. Era tudo certinho, certinho!...só que o ritmo era alucinado. Eu não respeitava os horários de alimentação, então dava certo no serviço, foi dando errado no meu corpo. Por exemplo o cara da padaria levava um pão doce e eu com a mesma mão suja que estava contando, eu ia comendo o pão doce..."

Marina também tinha seu trabalho organizado: “...eu nem gostava que vinham mexer nas minhas coisas, até para as pessoas ajudarem era complicado..."

Em todos os depoimentos pode-se perceber uma pressão interna e externa muito grande, quando não é a própria pessoa a se cobrar é o público que exige um atendimento rápido.

\section{LER: uma resposta do corpo ao sofrimento no trabalho?}

Apesar da existência de uma modelo econômico e de um sistema de produção, na prática o sofrimento fica individualizado, como bem coloca DEJOURS (1987) sobre o trabalho taylorizado que o paradoxo do sistema dilui as diferenças e individualiza o homem frente ao 
sofrimento. Isso ficou evidenciado nas entrevistas, cada uma delas relata uma história individual e um sofrimento particular, sendo na prática impossível compartilhar com outras pessoas.

Ana fala o seguinte: "Eu trabalhei dois anos com LER....Eu não estava enxergando, eu estava no embalo, no embalo...quando me dei conta, comecei a conversar com uma pessoa, com outra, eu falava: "Ah! Meu braço está adormecendo."

Um aspecto que chamou a atenção foi o fato das pessoas demorarem a procurar auxílio médico e o tratamento por várias razões, muitas vezes era abandonado.

Como fala Elisabete: "Quando eu descobri o primeiro sintoma eu procurei...Eu continuei a fisioterapia e trabalhando, tentando conciliar os horários...Era aquela correria..."

Ana fala em seu depoimento: "Eu não dava conta...Passava o dia inteiro no (banco)...Eu tinha tanta dor nas costas, era tanta dor nas costas, nas pernas, o meu pescoço ficava duro...e eu não sabia o que era, ia para massagista, eu não imaginava que aquilo era LER...trabalhei dois anos já com LER."

Sandra fala como começou seu adoecimento: "Quando eu estava na agência um dia minha mão travou em garra...era noite...fui à clínica...o médico me deu um relaxante muscular e uma semana afastada... a próxima vez que eu tive dor eu fui de novo na clínica...eu saía direto da agência para lá com dor e minha mão sem abrir e sem fechar...o médico falou.. é a segunda vez que você vem com o mesmo sintoma, você é bancária...isso está me parecendo LER."

A dor é muito forte e constante. Ana em seu depoimento aborda esta questão: " $E u$ não sei como meu pai, minha mãe e meu marido me agüentavam, porque a dor da LER é uma dor nojenta, ela acaba com o humor da gente. Eu fiquei um tempão sem ir na casa de ninguém, você quer mais é que o mundo se dane, você fica revoltada, é terrível."

Um aspecto importante da dor é que ela não é aparente, é subjetiva e individual. Os relatos demonstram haver muita discriminação como fala Elisabete: "Porque ela (gerente) é totalmente crítica da LER, ela tem uma postura assim. Outro dia ela perguntou para uma colega que estava afastada: Como é isso, você sabe que tem, qual o exame que faz pra saber que você tem LER? Porque aí ela fala que é psicológico, é de cabeça."

E toda subjetividade da dor acarreta sentimentos ambíguos ao doente, que muitas vezes duvida da sua própria doença ou se culpa por sua doença. Elisabete fala sobre isso: 
“...porque quando você está fora, você fica se sentindo meio fora, meio culpada. O pessoal está trabalhando e eu estou afastada e sentimentos assim passam...".

Nos depoimentos aparecem sentimentos de muita insatisfação, culpa, tristeza e medo; a começar pela percepção da doença e de se atribuir culpa pela LER ter aparecido e se desenvolvido sem conseguir fazer nada. Marina, por exemplo, durante quase todo o tempo ela se refere à LER como o "problema" somente no final ela disse a palavra LER: "Eu acho que a LER existe, ela se agrava muito com a tua cabeça, eu acho que é porque eu deixei a coisa fluir mais...Eu realmente estou com este problema, tenho este problema, por falta de cuidado não só meu, como da empresa também se eu soubesse que isso ia acontecer, eu teria me prevenido..."

Sandra fala da seguinte maneira: "Na época eu estava triste, muito decepcionada, estava me sentindo traída pelos chefes..."

Elisabete disse: “...eu estava meio estressada em todos os sentidos...eu estava empurrando com a barriga..."

Para Marina o sofrimento era grande: "Quando eu parei era porque eu precisava me tratar e eu não aguentava mais. Se eu não saísse pelo problema da LER, eu sairia pela psiquiatria, porque eu estava enlouquecendo naquele lugar."

Além de todo este sofrimento, existem as restrições impostas pelas LER, e que são sentidas no cotidiano, quando não se consegue mais realizar as coisas que se faziam, principalmente aquelas que traziam alegria e satisfação pessoal. Um depoimento que bem representou este aspecto foi o de Marina: "Mas você tem que saber que está limitada para algumas coisas...E isso me magoa muito...Outro dia nós fomos ao clube e meu marido e minhas filhas estavam jogando vôlei. E vôlei sempre gostei muito de jogar. Eu pensei naquele dia Eu vou jogar só um pouquinho, estou bem, acho que cinco minutos não farão mal. E fui jogar. Passei trinta dias com uma dor, uma dor horrivel (choro). E isso me magoa. Eu tive que mentir para a médica, porque eu não ia falar que eu fui jogar vôlei, eu tinha hematomas... Eu não me conformo com essas coisas." 


\section{DISCUSSÃO}

A primeira questão a ser analisada é a mudança nas relações de trabalho na sociedade contemporânea. O quadro atual do capitalismo pede não só às empresas, mas também à pessoas, flexibilidade.

SENETT (1999) coloca que a flexibilidade trouxe outros tipos de controle, ao invés de dar mais liberdade às nossas vidas, além de atuar seriamente sobre o caráter pessoal. As práticas de flexibilidade estão se tornando arraigadas na sociedade, é perfeitamente natural se falar em projetos ou campos de trabalho. Não pode mais existir apego ao passado.

As relações de trabalho não são mais duradouras como antigamente, os empregos para a vida toda não existem mais. Como conseqüência do redimensionamento das empresas, o emprego pode ser retirado ou a função ser extinta a qualquer hora. Isto também gera uma alteração no comportamento das pessoas. A empresa pesquisada teve que se adequar ao novo contexto; acompanhando as mudanças, implementou diversos processos administrativos como reengenharia, terceirização, qualidade total, entre outras. E este novo objetivo empresarial foi apresentado nas entrevistas como nocivo à saúde física e mental, pois descaracteriza o papel até então exercido pelos empregados como um todo.

ANTUNES (1995) afirma que a "classe que vive do trabalho sofreu a mais aguda crise deste século que atingiu não só a sua materialidade, mas teve profundas repercussões na sua subjetividade e, no íntimo inter-relacionamento destes níveis, afetou sua forma de ser." Se antes os trabalhadores de um banco tinham que atender aos clientes e resolver pendências contábeis, hoje fazem parte de uma equipe de vendas e é obrigatório que tenham uma visão comercial.

Há um dilema bastante moderno as mudanças rápidas e os valores de curto prazo já estão incorporadas ao cotidiano das pessoas, principalmente no reconhecimento de que não há mais espaço para a burocracia e a rotina, as demandas são de agilidade no atendimento, no pensamento, na introdução de novas tecnologias, por outro lado no íntimo as pessoas prezam pela confiança, lealdade, comprometimento, que são, pelo contrário valores de longo prazo. Está posto um novo desafio para a sociedade: encontrar uma forma de conciliar valores modernos com os antigos, ou seja, combinar o dinamismo com confiança mútua e compromisso. 
Um outro aspecto importante da mudança são as relações sociais no trabalho. A começar das chefias que hoje são vistas como facilitadores de processos e mediadores entre clientes e equipe. Porém na prática, isto não é percebido. Ainda continuam existindo chefias como antes. O poder adquirido através da autoridade formal, aquele que vem da burocracia, é ainda o que prevalece e é reconhecido pela base dos empregados e este não mudou. WEBER (1969) citado em MORGAN (1996) afirmou que a legitimidade é uma forma de aprovação social, trata-se do processo onde as pessoas reconhecem que alguém tem o direito de mandar em alguma área da vida humana, e o outro aceita essa condição. O medo de perder o emprego, o reconhecimento da autoridade, a dificuldade em lidar com figuras de autoridade são algumas das circunstâncias que impedem as pessoas de interferirem no sentido de acabar com as injustiças.

Além disso a relação com os colegas de trabalho também não estão satisfatórias. Os relatos são de competitividade entre as pessoas e principalmente falsidade nas relações, que são muito superficiais. A comunicação entre as pessoas também está inadequada, a forma como tarefas e informações são repassadas está ocorrendo de maneira insatisfatória. E no caso do banco isto é bastante complicado pois os trabalhadores devem estar atentos para as informações pois poderão ter prejuízos financeiros com erros, prazos, pressão de clientes, etc.

Um outro componente do trabalho são as estratégias pessoais adotadas dentro deste novo modelo. Para conseguir sobreviver dentro deste cenário as pessoas acabam adotando para si estratégias pessoais, como por exemplo, a forma como se alimentam durante o dia ou como organizam os documentos para poder não errar. O controle exercido sobre o trabalhador, quanto aquele que o próprio trabalhador exerce sobre si, pode suscitar insegurança e, dependendo da intensidade, vivências de sentimentos de perseguição, gerando ansiedade.

Um dos elementos que compõe a atividade laborativa e que faz parte da dinâmica geradora de perturbações na esfera mental é a densidade do trabalho, principalmente ligado às atividades cognitivas. WISNER (1987) observou que a demora para adormecer parece uma das conseqüências da densidade assumida pelo trabalho. As exigências feitas no trabalho são incorporadas pelos trabalhadores, que não conseguem visualizar e nem respeitar os seus próprios limites por causa da necessidade de produzir.

SATO (1991) em seu estudo sobre penosidade no trabalho, coloca que, na perspectiva psicossocial, o trabalho penoso é mais do que a exigência de esforços que 
provoquem incômodo e sofrimento, e sim quando estes sentimentos ultrapassam o limite do tolerável. Isso acontece quando o trabalhador não tem mais controle.

DEJOURS (1987), um estudioso no campo da psicopatologia do trabalho, faz uma reflexão sobre o sofrimento psíquico advindo da forma como o trabalho se organiza. Ele afirma que o sofrimento começa quando o trabalhador usou tudo que estava a seu alcance em termos de conhecimento e de poder na organização do trabalho, e mesmo assim ele não pode mais mudar nem sua tarefa, nem a forma como ela é feita.

Este sofrimento foi apresentado nos depoimentos das trabalhadoras, por exemplo quando elas referem ter uma forma, um método de trabalho que já não está mais adequado; tentaram mudar de posto inclusive, mas textualmente afirmaram que já não estavam mais conseguindo.

DEJOURS (1987) aborda em seus estudos a existência de um sistema coletivo de defesa contra o sofrimento que tem por objetivo mascarar, conter e ocultar uma ansiedade grave. Ele distingue três diferentes formas de ansiedade: relativa à degradação do funcionamento mental e do equilíbrio psicoafetivo; relativa à degradação do organismo, que resulta do risco sobre a saúde física e a ansiedade gerada pela "disciplina da fome", que é a necessidade de sobrevivência.

A demora pela busca de auxílio médico agravando o quadro de dor, denota nos depoimentos um sentimento de medo com relação ao futuro: o que aconteceria se elas não pudessem mais obter o valor monetário da função que exerciam, e também o que poderiam pensar e fazer as chefias: elas poderiam ser prejudicadas no trabalho; além disso poderiam ser vistas como aquelas que não conseguiram, como já havia acontecido com outras pessoas.

Dentro da mesma categoria de análise, um outro ponto importante é a respeito da principal característica da LER que é a dor. A dor é uma sensação muito particular, não existe uma definição exata que consiga abranger toda a dimensão da dor, pois ela é subjetiva e pertence a cada um.

FERREIRA (1998) em seu estudo fala sobre as diversas descrições da dor e afirma que as mesmas metáfora usadas para a descrição da dor física, também são usadas para explicar um sofrimento moral, assim a dor é sempre uma sensação desagradável, podendo suscitar questões comuns a qualquer tipo de sofrimento ao percebê-la como forma de punição: "Por que eu? O que eu fiz para merecê-la?". Nos depoimentos a dor aparece mais 
forte quando as pessoas não encontram mais condições de mudar o seu cotidiano no trabalho, havendo muita pressão externa e interna.

A dor é subjetiva e a LER é basicamente dor. Os relatos demonstram haver discriminação feita através de insinuações maldosas, como por exemplo a inexistência da doença pois ela não é aparente, que é somente desculpa para não trabalhar. Isso acarreta sentimentos ambíguos ao doente, que muitas vezes duvida de sua doença e acaba sentindo mais dor, na tentativa de justificar o seu afastamento e poder também acreditar nela. Muitas vezes os comentários são de que a LER é uma doença psicológica, deixando para o doente a culpa pela doença, como se ele fosse uma pessoa fraca.

Assim a dor assume uma dimensão bastante importante na vida das pessoas com LER, seja pela questão física e mental, ou pela discriminação vinda através de sua subjetividade.

\section{CONCLUSÕES}

Pela análise dos dados levantados, pode-se constatar a complexidade que envolve a questão das LER. As pessoas que têm LER revelam isso em seus depoimentos, percebendo a variedade das causas que levaram a seu adoecimento. A sociedade vive hoje um período de instabilidade econômica, social e emocional, sendo extremamente comum encontrar pessoas conversando sobre o medo de perder seu emprego. Esta instabilidade ocorre a nível mundial. $O$ emprego deixou de ser sinônimo de segurança. Em muitos países trabalha-se por projetos, sendo as pessoas contratadas para atuar em determinado assunto e com prazo definido. A pessoa sente estar perdendo a sua dignidade sendo essa, entre outras, uma das causas do medo do desemprego, o que as leva a se submeterem a qualquer condição que thes seja imposta. Quem se beneficia com isso é o processo produtivo, o medo gera ansiedade, tensão, além do empenho para mostrar capacidade, envolvimento, dedicação, é a roda viva da sobrevivência.

As pessoas envolvidas neste processo mudaram seu comportamento e com elas as relações sociais dentro da empresa, não existe mais a necessidade das pessoas se conheceram mais do que o suficiente para cumprirem suas tarefas, a competição ficou mais acirrada. Percebe-se que a insatisfação é grande e para algumas pessoas isso se traduz no adoecimento e neste caso, através das LER. Portanto, não se trata apenas de um 
problema ortopédico, mas sim de uma multiplicidade de fatores evidenciando a importância dos aspetos psicossociais.

Em conclusão pode-se apresentar:

- Interferência da organização do trabalho e das relações de trabalho no adoecimento, considerando o cenário econômico atual e a agressividade do processo produtivo.

- O sofrimento físico e mental que antecede e precede o adoecimento, confundindo-se as duas dimensões, tornado-se muitas vezes uma dor moral.

- Onipresença da dor e as limitações impostas a nivel físico e mental que impossibilitam projetos de vida.

- Dificuldades no diagnóstico e tratamento e no auto reconhecimento da doença

- Comprometimento da vida pessoal e familiar, dificultando o desempenho dos diversos papéis

As ações em torno das LER não podem deixar de lado os aspectos psicossociais, quais sejam organização do trabalho, relações sociais, sofrimento psíquico, desgaste mental, entre outros. Tais ações devem ocorrer conjuntamente: governos se interessarem na gravidade da situação e atuarem na legislação; empresas irem além do normativo, implementando ações preventivas e de promoção da saúde; indivíduos participarem do contexto procurando exercer seu direito à cidadania, entendendo que somos nós que fazemos a história.

\section{REFERÊNCIAS BIBLIOGRÁFICAS}

ANTUNES, R. Adeus ao trabalho? ensaio sobre as metamorfoses e a centralidade do mundo do trabalho. São Paulo: Cortez, 1995.

ARMSTRONG, T.J. Ergonomics and cumulative trauma disorders. Hand Clinics. v. 2, n. 3, p. 553-65, 1986

BROWNE, C.D.; NOLAM, B.M.; FITHFULL, D.K. Occupational repetition strain injuries: guidelines for diagnosis and management. Medical Journal of Australia, v. 140, n. 6, p. 329-32, 1984.

DEJOURS, C.A. Loucura do trabalho. São Paulo: Oboré, 1987. 
FERREIRA, J. Corpo sígnico. In: ALVES, P.C.; MINAYO, M.C. de S. Saúde e doença: um olhar antropológico. Rio de Janeiro: FIOCRUZ, 1998. p. .

FLEURY, A.; FLEURY, M.T.L. Aprendizagem e Inovação Organizacional. São Paulo: Atlas, 1995.

HOUTMAN, I.L., et aL. Psychosocial stressors at work and musculoskeletal problems. Scandinavian Journal Environement Health, v. 20 n. 2, p. 139-45,1994.

HUNTING, W, et al. Postural and visual loads at VDT work places I constrained postures; II lighting conditions and visual impairmentes. Ergonomics, London, v. 24, n. 12, p. 917$44,1981$.

LECLERC, A. et al Study group on repetitive work: "Carpal tunnel syndrome and work organition in repetitive work; a cross study in France". Occupational Enviroment Medicine, v. 55 , p. 180-7,1998.

LÜDKE, M.; ANDRÉ, M.E.D. Pesquisa em educação: abordagens qualitativas. São Paulo: Temas Básicos em Educação e Ensino, 1990.

LUFT, C.P. Mini dicionário. 5ª Ed., São Paulo; Ática/Scipione, 1994.

MAEDA, K. Occupational cervicobrachial disorder and its causative factors. Journal Human Ergology, Tokio, v. 6, p. 193-202, 1997.

MARX, K. Capital. Harmondesworth: Penguin, 1976. In: MORGAN, G. Imagens da Organização. São Paulo: ATLAS, 1996.

MINAYO, M.C. de S. O desafio do conhecimento: pesquisa qualitativa em saúde. São Paulo: HUCITEC; Rio de Janeiro: ABRASCO, 1992.

MINISTÉRIO DA PREVIDÊNCIA SOCIAL. Portaria 4698, de 17/08/98: dispõe sobre as normas técnicas para DORT, PAIR, benzenismo e pneumoconioses. Diário Oficial da República Federativa do Brasil, Brasília, 19 ago, 1998.

MORGAN, G. Imagens da Organização. São Paulo: Atlas, 1996.

OHISSON, K. et al. Repetitive industrial work and neck and upper limb disorders in females. American Journal Industrial Medicine, v. 27, p. 731-47, 1995.

OHNO, T. Workplace Management. Cambridge: Productivity, 1988.

RAMAZZINI, B. As doenças dos trabalhadores. São Paulo: FUNDACENTRO, 1985. 
RIBEIRO, HP. Lesões por esforços repetitivos (LER): uma doença emblemática. Cadernos de Saúde Pública, Rio de Janeiro, v. 13 n. supl.2, p. 85-93, 1997.

SATO, L. Abordagem psicossocial do trabalho penoso: Estudo de caso de motoristas de ônibus urbano. São Paulo, 1991. [Dissertação de Mestrado em Psicologia Social da Pontifícia Universidade Católica de São Paulo]

SATO, L., et al. Atividade em grupo com portadores de LER e achados sobre a dimensão psicossocial. Revista Brasileira de Saúde Ocupacional, v. 79, n. 21, p. 50-62, 1993.

SECRETARIA DE ESTADO DA SAÚDE. Resoluções 180 e 197: Dispõe sobre Norma Técnica para LER. São Paulo, 1992.

SENNETT, R. A corrosão do caráter: conseqüências pessoais do trabalho no novo capitalismo. Rio de Janeiro: RECORD, 1999.

SINDICATO DOS BANCÁRIOS DE SÃO PAULO - SEEB/SP. Um estudo sobre o perfil da categoria bancária. São Paulo: SEEB, 1989.

TAYLOR, F.W. Princípios da administração científica. São Paulo: ATLAS, 1970.

WILHELMINA, E. et al. Physical load during time as risk factors for back pain. Scandinavian Journal of Environ Health., v. 25, n. 5, p. 387-403, 1999.

WISNER, A. Por dentro do trabalho: ergonomia, método e técnica. São Paulo: FTD/Oboré, 1987. 


\section{REPETITIVE STRAIN INJURY: A REFLECTION ON PSYCHOSOCIAL ASPECTS}

SUMMARY: The aim of this study was contributing to the understanding of the phenomena that involves the Repetitive Straisn Injury (RSI) and its relation with the work arena. It was carried out through the reflection on the multiplicity of factors and emphasis on the psychosocial dimension based on the statements of people affected by RSI. The qualitative method was used and the case study tool was chosen based on the characteristics of the research clerks on leave for RSI diagnosis were interviwed. Individual semi strutured interwiews were carried out on previously scheduled occasions - each one lasting around two hours. The interviewees showed discredit in their sickness; dissatisfaction and revolt for no longer being able todo important things in their personal lives; difficulty in showing the illness and making people believe in it, lack of recognitions for work done; identity loss, anxiety before the unknown, heightened stress and strain and also limitations posed by the illness. In conclusion, it coult be observed that there was interference with the work organitation and work relations on getting sick, physical and mental suffering preceding the illness; ubiquity of pain and phisycal and mental limitations which make life projects impossible; difficulties in the diagnosis and treatment and finally endangerment of their personal and family life.

KEYWORDS: repetitive strain injury; psychosocial aspects; bank work. 


\section{ROTEIRO DA ENTREVISTA}

1) Fale sobre sua vida pessoal.

2) Há quanto tempo trabalha no banco?

3) Em que locais você já trabalhou no banco?

4) Quando você se afastou, onde você trabalhava?

5) Como era seu ambiente de trabalho?

6) O que você fazia e como desenvolvia suas tarefas? Havia uma estratégia pessoal?

7) O que você via como problemas para o desempenho de sua função?

8) Como era a comunicação na sua Unidade? Como eram passadas as informações?

9) Como você sabia o que devia fazer?

10) Como era trabalhar na sua Unidade?

11) Como era o relacionamento entre as pessoas?

12) Como você considera o seu trabalho na sociedade?

13) Como você percebe seu estado de saúde?

14) A que causas você atribui ter adquirido esta doença?

15) Como você descreve seu estado mental na ocasião do afastamento?

16) E hoje, como esta? 